to ward off epidemics, such as a 'black wedding' in a Jewish graveyard in Odessa. And we're reminded that there is scarcely a cemetery anywhere from the time without a cluster of victims' tombstones.

The pandemic burnt out in 1920, but its impact persisted in communities and nations doubly devastated by war and pestilence. Many governments, shaken by their failure to control it, recognized that infectious disease was not the sole responsibility of the individual. By the mid-1920s, most European countries had established health-care programmes. Germany and Britain expanded their rudimentary prewar systems. The newly created Soviet Union set up a centralized organization for urban communities, emphasizing public health. US health surveys and morbidity reporting were coordinated by 1925; a National Quarantine Service was established in China in 1930. Laboratory expertise in epidemiology, virology and pharmacology burgeoned. The Rockefeller Foundation in New York City became an important player in international public health, and the Pasteur Institute in Paris established its first overseas branch, in Tehran, to study infectious disease.

Now, with new epidemics exacerbated by rapid and constant international movement of people, animals and virulent organisms, governments are braced for a future flu pandemic. The questions 'when' and 'how big' dominate; bodies such as the World Health Organization and the US Centers for Disease Control and Prevention monitor climate change and disease outbreaks, assess evolving viral strains for potential vaccines and prepare emergency lab networks and surveillance systems. Epidemiological models estimate death tolls of 20 million to 100 million - still terrifying, albeit a lower proportion of the global population than in 1918. Quarantine, prohibition of large gatherings, and mass vaccination will play their part - all lessons learnt a century ago.

Along with exemplary research, Spinney's narrative is packed with fascinating, quirky detail — such as the royal rebranding of the Real Madrid football team as part of a post-flu 'sports for health' movement. US President Donald Trump even makes an appearance: an inheritance from his flu-victim grandfather seeded the family's property empire.

As the centenary of this monumental event approaches, other volumes on the pandemic will undoubtedly appear. Pale Rider sets the bar very high.

Tilli Tansey is professor of the history of modern medical sciences at Queen Mary, University of London.

e-mail:t.tansey@qmul.ac.uk

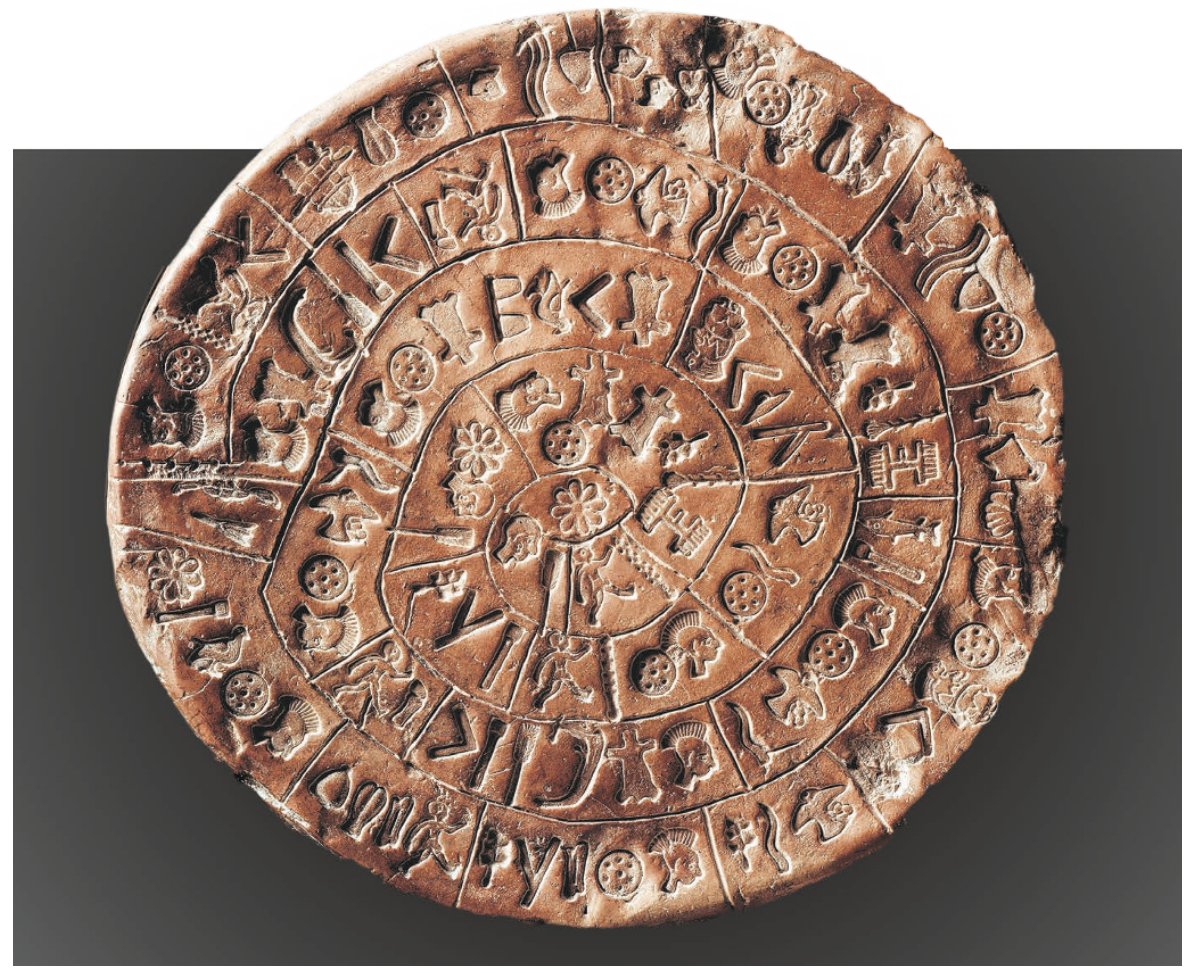

The Phaistos disc, discovered in Crete in 1908, remains untranslated.

CRYPTOGRAPHY

\title{
The codes that got away
}

\section{Andrew Robinson takes on a compendium of past and current ciphers ripe for decoding.}

$\mathrm{T}$ The concluding words of Unsolved! are a call to action. Craig Bauer, a US mathematician and editor-in-chief of the journal Cryptologia, ends his hefty history of cryptography by noting that even as he was compiling the book, "unsolved ciphers from decades, sometimes centuries, in the past were coming to light on a regular basis", along with a plethora of new puzzles. For cryptography fiends, it's a thrown gauntlet.

Unsolved! spans a huge arc of time and space, from Julius Caesar's simple substitution cipher to composer Edward Elgar's 1897 Dorabella Cipher - a still-unsolved letter to Dora Penny, a dedicatee of his Enigma Variations. Uncracked ciphers from the twentieth century are associated with the Irish Republican Army, a series of grisly murders in California - and messages 'detected' from Mars.

Bauer's compelling chapter on the medieval Voynich manuscript occupies one-sixth of the book. In his 1967 The Codebreakers, cryptography historian David Kahn called the manuscript "the longest, the best known, the most tantalizing, the most heavily attacked, the most resistant, and the most expensive of historical cryptograms". Its weird colour illustrations and indecipherable calligraphy attract $16 \%$ of online traffic to the library at Yale University in New Haven, Connecticut, where it is held (A. Robinson Nature 539, 28-29;

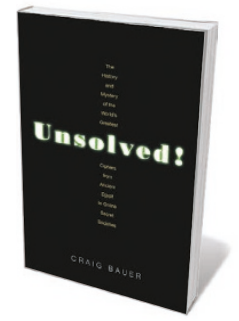

Unsolved! The History and Mystery of the World's Greatest Ciphers from Ancient Egypt to Online Secret Societies

CRAIG BAUER Princeton University Press: 2017.

\section{Bauer offers no theories of his own.)}

Unsolved! digs into the riches of ancient Viking, Roman, Greek and Egyptian cryptography. Egyptologists tend to avoid tackling the latter because of its sheer complexity. Bauer reveals how Caesar's cipher worked, substituting each plain-text letter with a letter a fixed number of places away in the alphabet. Inexplicably, however, he relegates to an endnote the undeciphered Phaistos disc found on Crete in 1908 - the only example of its 
much-discussed script (A. Robinson Nature $453,990-991 ; 2008)$. Nor is there even a passing reference to Michael Ventris, celebrated for his 1952 decipherment of the script Linear $B$ as a form of archaic Greek, or to the exciting solution of Central America's Mayan script, launched by Soviet linguist Yuri Knorozov.

Perhaps the most successful chapter centres on ciphers by the notorious, never-captured 'Zodiac Killer', who murdered at least five people in California in 1968-70 (dramatized in David Fincher's 2007 film Zodiac.) The murderer sent taunting letters to local newspapers, featuring four ciphers offering clues to his identity. The first was broken by husband-and-wife amateurs Donald and Bettye Harden. She guessed that a self-centred person might begin his message with 'I'; that 'KILL' might feature in it more than once; and even that the phrase 'I LIKE KILLING' might appear. This proved the key to translating the simple MASC to meaningful, if misspelt, English, although no sense could be made of the killer's signature, EBEORIETEMETHHPITI.

The Zodiac's other ciphers have proved resistant. Bauer hazards that a nine-letter 'word' with some resemblance to the tenletter 'CALIFORNIA' may mean just that, although a letter is missing - possibly due to "lousy spelling". But would a killer with poor spelling, as opposed to someone like the wordplay-loving Elgar, be attracted to ciphering? Later, Bauer guesses that such misspellings were "likely intentional".

The level of decoding skill needed for Unsolved! varies significantly. A willingness to grapple with plain text and cipher text is necessary, but some parts require undergraduate-level mathematics. One is the section on RSA, unveiled in the 1970s as one of the first practical public-key cryptosystems. The book's combination of convincing logic and sometimes-convincing speculation is a familiar mix to those of us interested in undeciphered writing, such as the script of the Indus civilization (A. Robinson Nature 526, 499-501; 2015) and the rongorongo script used on Easter Island.

As science-fiction writer Arthur C. Clarke commented when I published Lost Languages (McGraw-Hill, 2002): "Many, it seems likely, will never be deciphered which raises an interesting question. If we cannot always understand messages from our fellow humans - how successful will we be when we receive the first communication from Outer Space?" And Clarke was talking about ordinary writing systems. For all the clues analysed in Unsolved!, there is plenty of Earthly decoding to do before we tackle any extraterrestrial communiqués.

Andrew Robinson is the author of Cracking the Egyptian Code and Writing and Script: A Very Short Introduction. e-mail:andrew@andrew-robinson.org

\section{Books in brief}

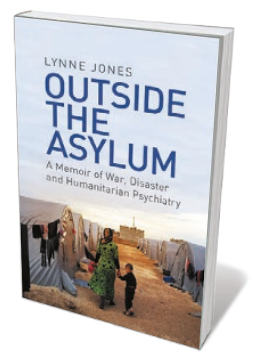

Outside the Asylum

Lynne Jones WEIDENFELD \& NICOLSON (2017)

How do you help a poverty-stricken child whose parents were killed in front of her? For psychiatrist Lynne Jones, such layered traumas are a life's work: she has practised in war and disaster zones from Bosnia to Haiti for more than two decades. Her blazingly frank account is as enlightening on shifts in psychiatric treatment as it is on local implications of humanitarian-aid policy. Observing the impossible lives that millions somehow live in troubled regions, she is clear on the meaning of asylum and what keeps her at this front line: not the suffering, but "the proximity to courage". Brilliantly insightful.

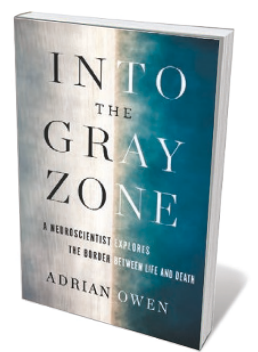

Into the Gray Zone

Adrian Owen SIMON \& SCHUSTER (2017)

In 2006, neuroscientist Adrian Owen made a discovery with profound implications for science, medicine and law: up to one-fifth of people in a 'vegetative state' following traumatic brain injury are cognitively intact. Meshing memoir with scientific explication, Owen reveals how functional magnetic resonance imaging can probe the deep space of trapped minds. It's a riveting read, from the march of technology and tests for neural responses — such as imagining playing a game of tennis - to extraordinary personal accounts of the "gray zone" by partially recovered patients.

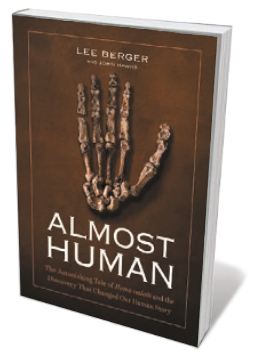

\section{Almost Human}

Lee Berger and John Hawks NatiOnAL GeOGRAPHIC (2017)

Palaeoanthropologist Lee Berger has a knack for finding both fossils and the public limelight. This memoir focuses on Homo naledi, a small-brained species of human relative discovered in a cramped cave system near Johannesburg. If this sounds familiar, that's probably because it is. Berger and co-author John Hawks live-blogged their 2013 excavation, which recovered hundreds of hominin fossils, and last month held a live-streamed press conference to announce the fossils' age (a young 300,000 years old). This is a fine account of the thrills of plumbing the mysteries of human evolution.

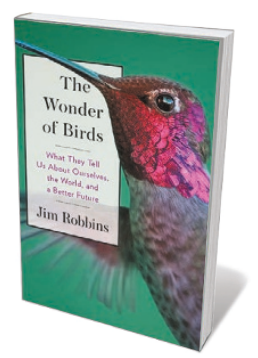

\section{The Wonder of Birds}

Jim Robbins VIKING (2017)

Birds are central to science far beyond ornithology, reminds Jim Robbins. Aeronautics, dinosaur locomotion and migration have all drawn hugely from the study of avifauna, and human culture has embraced the winged beasts as a potent metaphor for transformation. As Robbins gazes at a murmuration of dunlins to ponder "swarm intelligence", bands owls with feisty field biologist Denver Holt, contemplates the bone-snapping beak of a vulture and muses over the complex calls of the chickadee, it's hard not to share his wonder at the biological riches of the 10,000 species.

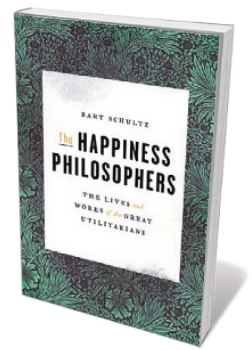

\section{The Happiness Philosophers}

Bart Schultz PRINCETON UNIVERSITY PRESS (2017)

"The greatest happiness of the greatest number." The aim of utilitarianism - the nineteenth-century philosophy founded by the likes of William Godwin and Jeremy Bentham — seems baldly 'worthy'. But as Bart Schultz argues in this adroit study, the ethical theories of these men, forged in a politically chaotic era, remain relevant in our own. Schultz journeys beyond the caricatures to reveal their deep influence on education, law and, in Bentham's case, surprisingly modern thinking about homosexuality. Barbara Kiser 